\title{
Регистрация терагерцового излучения с помощью наноструктур карбида кремния
}

\author{
(C) Н.Т. Баграев ${ }^{1,2}$, С.А. Кукушкин ${ }^{1}$, А.В. Осипов ${ }^{1}$, Л.Е. Клячкин ${ }^{2}$, А.М. Маляренко ${ }^{2}$, В.С. Хромов ${ }^{1,2}$ \\ ${ }^{1}$ Институт проблем машиноведения Российской академии наук, \\ 199178 Санкт-Петербург, Россия \\ ${ }^{2}$ Физико-технический институт им. А.Ф. Иоффре Российской академии наук, \\ 194021 Санкт-Петербург, Россия \\ E-mail: bagraev@mail.ioffe.ru, sergey.a.kukushkin@gmail.com
}

Поступила в Редакцию 28 июля 2021 г.

В окончательной редакции 2 августа 2021 г.

Принята к публикации 2 августа 2021 г.

\begin{abstract}
Исследуется отклик наноструктур карбида кремния, полученных методом согласованного замещения атомов, на внешнее терагерцовое излучение. Регистрируется кинетическая зависимость продольного напряжения при комнатной температуре в условиях пропускания продольного тока исток-сток в структурах с холловской геометрией. В рамках предлагаемой модели квантового эффекта Фарадея падающее излучение приводит к возникновению генерационного тока в краевом канале при изменении числа квантов магнитного потока и соответственно к проявлению особенностей в кинетической зависимости продольного напряжения. Исследована генерация собственного терагерцового излучения в наноструктурах карбида кремния методом регистрации спектра электрически детектируемого электронного парамагнитного резонанса при измерении магнетополевых зависимостей продольного напряжения.
\end{abstract}

Ключевые слова: карбид кремния на кремнии, терагерцовое излучение, наноструктура, ЭДЭПР, квантовый эффект Фарадея.

DOI: 10.21883/FTP.2021.12.51705.9620

\section{1. Введение}

В настоящее время значительное внимание направлено на исследования, связанные с получением и использованием терагерцового (ТГц) излучения, к которому относят область частот $0.1-10$ ТГц $\left(1\right.$ ТГц $=10^{12}$ Гц, чему соответствуют длина волны $\sim 300$ мкм, энергия $\sim 4.14$ мэВ). Это излучение обладает рядом характеристик, которые делают перспективным его применение в различных областях.

Интенсивно исследуются возможности применения ТГц излучения в биологии и медицине. В терагерцовом диапазоне находятся энергии колебательных переходов в молекулах, что позволяет использовать ТГц излучение для их идентификации и исследования, в частности для изучения ДНК [1], а также для детектирования нуклеиновых кислот, углеводов, протеинов и пептидов [2]. Терагерцовое излучение не является ионизирующим и не повреждает биомолекулы, так как энергия фотонов мала по сравнению с энергией ионизации, которая может привести к атомной или молекулярной диссоциации [3]. Эксперименты показывают, что оно влияет на проницаемость мембран эритроцитов, что может стимулировать высвобождение гемоглобина [4]. Также сообщается, что ТГц излучение подавляет экспрессию генов, ассоциированных с различными кожными заболеваниями [5]. Наконец, интенсивное поглощение водой и жидкостями организма ТГц излучения делает перспективным его применение для ранней диагностики онкологических заболеваний [1].
Вызывает большой интерес и применение ТГц излучения в телекоммуникациях [6]. Так, в работе [7] исследовалась содержащая фотонную интегральную схему на базе кремния ТГц коммуникационная система с возможностью беспроводной передачи сигнала-кода без возвращения к нулю (non-return-to-zero) со скоростью 40 Гб/с. Сообщается о возможности передачи данных со скоростями > 100 Гб/с несущей волной 0.3 ТГц более чем на 110 м [8].

Для ТГц излучения являются прозрачными неполярные и неметаллические материалы, такие как бумага, пластик, одежда, дерево, керамика. Поэтому ТГц излучение может применяться в сфере безопасности для обнаружения спрятанных объектов без вреда для человека, в отличие от рентгеновских лучей. Кроме того, явления, происходящие в материалах при отклике на ТГц излучение (вращательные переходы в молекулах, колебания решетки в твердых телах, колебательное движение с большой амплитудой в органических соединениях), могут быть использованы для детектирования взрывчатых веществ, химического и биологического оружия [6].

Изначально для детектирования инфракрасного (ИК) и ТГц излучения использовались термометры. Тепловые эффекты вследствие падающего излучения лежат в основе класса так называемых термодетекторов ТГц излучения. К ним относится ячейка Голея, где в условиях падения излучения на поглотитель нагрев последнего передается моноатомному газу (аргон или ксенон), изолированному внутри ячейки с мембранной стенкой. Расширение газа деформирует стенку мембра- 
ны с зеркальной поверхностью, на которую подается излучение от светодиода. Отраженное от зеркальной стенки излучение попадает на фотодиод, освещенность которого зависит от степени деформации зеркала [9]. В твердотельных образцах изменение температуры приводит к изменению спонтанной поляризации в образцах из пироэлектрического материала; среди часто используемых выделяют триглицинсульфат (TGS) и дейтерированный триглицинсульфат (DTGS). Поглощение тепла вызывает изменение величины электрического поля между противоположными гранями образца, которое может быть зарегистрировано [9]. Подобные термодетекторы способны работать при комнатной температуре, однако недостаточно чувствительны для детектирования излучения с малой интенсивностью, а также восприимчивы к перемещению и вибрациям, в особенности пироэлектрические детекторы, которые также являются пьезоэлектриками [9]. В полупроводниковых болометpax, охлажденных до низких температур, вследствие замораживания носителей заряда сильно повышается сопротивление. При поглощении ТГц квантов носители переходят в зону проводимости, что отражается в регистрируемом падении сопротивления [9]; одним из часто используемых материалов является теллурид кадмия-ртути (МСТ). Несмотря на быстроту отклика и высокую чувствительность, применение подобных детекторов ограничено необходимостью охлаждения до криогенных температур [9]. Попытки обойти это ограничение предпринимались при использовании приборных структур на основе материалов ВТСП [10], однако возникающие технологические сложности реализации воспроизводимых приборных характеристик не позволили развить это направление.

Также ТГц излучение может взаимодействовать с носителями в детекторе, который при этом относят к классу так называемых электронных. Лежащие в основе их работы эффекты могут основываться на коллективном поведении носителей (взаимодействие ТГц излучения с волнами плазмы в канале полевого транзистора, которое можно описать с помощью гидродинамической аналогии [11]) или же на взаимодействии фотонов с индивидуальными носителями (например, прохождение носителя заряда через потенциальный барьер в диоде Шоттки). Подобные детекторы обычно работают при комнатной температуре и имеют малый размер, что позволяет создавать массивы структур. К недостаткам относят узкополосный характер детекторов, что в случае с детекторами транзисторного типа требует применения нескольких антенных структур [9].

Приемники ТГц излучения могут рассматриваться как отдельные от источника устройства, так и тесно связанные с ним. Так, в технике self-mixing часть испущенного из лазера излучения возвращается в резонатор и модифицирует параметры работы лазера, при этом амплитуда и фаза такого переизлученного сигнала могут быть зарегистрированы [12]. Такая техника интерферометрии с использованием квантового каскадного лазера была применена для визуализации состояния биотканей [13]. Недавние исследования показали, что подобная техника может быть реализована для диагностики онкологических заболеваний с использованием в качестве источника ТГц излучения полупроводниковых наносандвичей на основе кремния, сильно легированного бором [14]. Излучение в этих наносандвичах генерируется краевыми каналами, ограниченными дипольными центрами, которые формируют сетки джозефсоновских переходов [15]. Недавно было обнаружено, что в качестве основы для излучателя на базе наносандвича может быть использован карбид кремния, что повышает мощность излучения [16]. Поэтому актуальной является проблема исследования возможности детектирования ТГц излучения при комнатной температуре с помощью такого наносандвича.

\section{2. Методика эксперимента}

В качестве основы для детектора были использованы полупроводниковые образцы с выращенными на поверхности монокристаллического кремния пленками монокристаллического $\mathrm{SiC}$. Техника их получения методом согласованного замещения атомов с использованием химической реакции кремния с газом монооксида углерода была представлена в серии работ [17-19]. Подробное описание протекающих при этом процессов приведено в обзорах $[20,21]$.

В сравнении с другими методами данный механизм роста пленок $\mathrm{SiC}$ отличается тем, что сохраняется строение исходной кубической решетки $\mathrm{Si}$, чем обеспечивается рост именно кубического политипа $3 C-\mathrm{SiC}$ [20-22]. Это подтвердили электронно-микроскопические исследования, которые также показали отсутствие дислокаций несоответствия решеток на границе раздела $3 C-\mathrm{SiC}(111) / \mathrm{Si}(111)$, вместо которых на межфазной границе присутствуют дефекты упаковки с прослойками гексагональных фаз [23]. Под термином „согласованный“ подразумевается, что процессы удаления атома $\mathrm{Si}$ из решетки и встраивания на его место атома С в ходе реакции

$$
2 \mathrm{Si}(\text { crystal })+\mathrm{CO}(\text { gas })=\mathrm{SiC}(\text { crystal })+\mathrm{SiO}(\text { gas }) \uparrow
$$

происходят одновременно [22]. Эпитаксия пленок карбида кремния на кремнии за счет согласованного замещения половины атомов $\mathrm{Si}$ на атомы С в условиях упомянутого отсутствия дислокаций несоответствия обеспечивает высокое кристаллическое совершенство пленок $\mathrm{SiC}$ [20-23].

Синтез карбида кремния по схеме реакции (1) протекает в два этапа. Вначале образуются комплексы кремниевая вакансия - межузельный атом углерода. Затем происходит смещение атомов углерода по направлению к кремниевым вакансиям с образованием карбида кремния. Активированные комплексы превращаются в карбид кремния, а под слоем $\mathrm{SiC}$ освободившиеся вакансии 
собираются в поры. В результате происходит образование пленки карбида кремния, которая частично висит над порами в кремнии. Этим объясняется отсутствие упругих напряжений в пленках, полученных данным методом [17-23]. При этом в отличие от традиционных методик выращивания ориентация пленки задается „старой“ к кристаллической структурой исходной кремниевой матрицы, а не только поверхностью подложки.

В данном способе синтеза карбида кремния методом согласованного замещения атомов важной особенностью является то, что на границе раздела $\mathrm{SiC} / \mathrm{Si}$ появляется интерфейсный слой толщиной порядка нескольких нанометров с нестандартными оптическими и электрофизическими свойствами. Это вызвано тем, что на завершающей стадии превращения кремния в карбид кремния происходит процесс усадки исходной решетки материала $\mathrm{Si}$ с параметром 0.543 нм, которая „схлопывается“ в кубическую решетку $\mathrm{SiC}$ с параметром 0.435 нм; процесс этот происходит в плоскости подложки [20,23]. При этом отделившийся от кремниевой матрицы карбид кремния подвергает ее аномально сильному сжатию, величина которого превышает 100 ГПа. При таких высоких давлениях получение $\mathrm{SiC}$ со столь упорядоченной структурой было бы невозможно без совпадения каждой пятой кристаллической ячейки карбида кремния с каждой четвертой ячейкой кремния с высокой точностью. Усадка материала приводит к согласованному расположению каждой пятой химической связи $\mathrm{SiC}$ с каждой четвертой связью Si. Остальные связи либо рвутся, что приводит к возникновению вакансий и пор, либо подвергаются сжатию, что приводит к изменению структуры поверхностных зон прилегающего к $\mathrm{Si}$ карбида кремния и его превращению в „полуметал ““. Впервые это явление было недавно обнаружено методом спектральной эллипсометрии в диапазоне энергий фотонов 0.5-9.3 эВ [24].

Из квантово-химических расчетов [24] следует, что в процессе бездислокационного согласования различающихся на $20 \%$ решеток $\mathrm{SiC}$ и $\mathrm{Si}$ пленка $\mathrm{SiC}$, обращенная к подложке $\mathrm{Si}$-поверхностью, притягивает один из 16 атомов $\mathrm{Si}$ в ближайшем двойном слое атомов подложки. При этом 22 из 25 атомов $\mathrm{Si}$ образуют химические связи с атомами $\mathrm{Si}$ подложки, а 3 атома из 25 (т.е. 12\%) не образуют связей из-за слишком далекого расположения от атомов подложки (> $3 \AA$ ). Именно от этих атомов $\mathrm{Si}$ в $\mathrm{SiC} p$-электроны дают основной вклад в узкий и резкий пик плотности электронных состояний $3 C-\mathrm{SiC}(111) / \mathrm{Si}(111)$, находящийся в окрестности энергии Ферми. Иначе говоря, граница раздела $3 C-\mathrm{SiC}(111) / \mathrm{Si}(111)$ должна проявлять необычные электрофизические свойства; в частности, она должна хорошо проводить электрический ток.

Эта граница проявляет также и ряд необычных магнитных свойств. В работе [25] исследовался образец с выращенной на кремнии (110) пленкой карбида кремния, после формирования которой было выполнено легирование бором в условиях неравновесной диффузии из газовой фазы; технологические параметры для

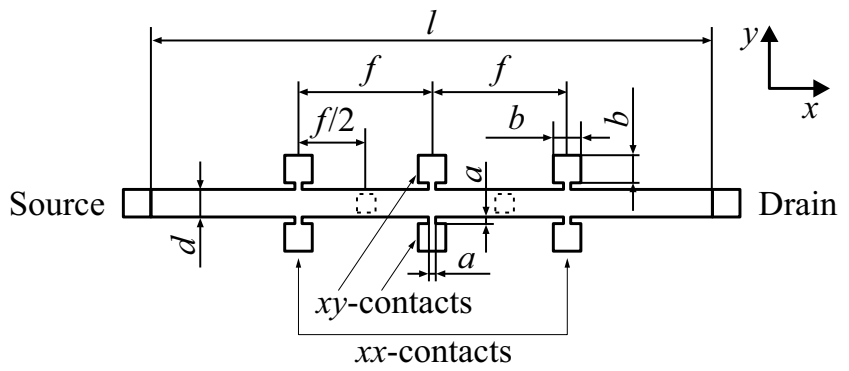

Рис. 1. Холловская геометрия контактов на поверхности исследуемой структуры на основе $\mathrm{SiC}$. Параметры в мкм: $a=50$, $b=200, d=200, l=4200, f=1000$. Пунктиром показаны месторасположения вертикальных контактов размера $b \times b$, сформированных над поверхностью структуры.

этого образца (Ф5) указаны в [25]. Обнаруженный „диа-пара-гистерезис“ магнитной восприимчивости соответствует экспериментальной демонстрации эффекта Мейснера-Оксенфельда. Также были обнаружены осцилляции магнитной восприимчивости, идентифицирующие реализацию условий квантовой интерференции в окрестностях микродефектов в плоскости образца. Исследование этих осцилляций позволило идентифицировать эффекты де Гааза-ван Альфена (дГвА) и Ааронова-Бома (АБ), связанные с квантованием момента и магнитного потока при комнатной температуре соответственно, что реализуется благодаря эффективному подавлению электрон-электронного взаимодействия при высоких температурах. Это оказывается возможным благодаря формированию дипольных центров бора с отрицательной корреляционной энергией, которые ограничивают краевые каналы рассматриваемой структуры и благодаря взаимодействию с носителями определяют характеристики осцилляций дГвА и АБ [26]. Следует отметить, что кроме дипольных центров бора формировать краевые каналы могут дипольные центры типа кремниевая вакансия - межузельный атом углерода, которые всегда присутствуют в структурах $\mathrm{SiC} / \mathrm{Si}$, выращенных методом согласованного замещения атомов на поверхностях кремниевой подложки (111) и (110) [22]. Таким образом, наблюдение квантовой интерференции в краевых каналах взаимосвязано с отмеченным выше „Диа-пара-гистерезисом“ магнитной восприимчивости.

Для проведения экспериментов в условиях пропускания тока через такой образец-детектор на основе карбида кремния на его поверхности были сформированы контакты в холловской геометрии, показанные на рис. 1 .

Для проведения экспериментов была реализована измерительная схема, показанная на рис. 2, $a$. Исследуемый образец-детектор на основе карбида кремния располагался на расстоянии $s$ от источника ТГц излучения. Детектор находился в металлической защитной коробке с отверстием, перед которым был помещен ТГц фильтр Tydex LPF14.3, препятствующий прохождению излучения с частотами $>14.3$ ТГц. В качестве источника 

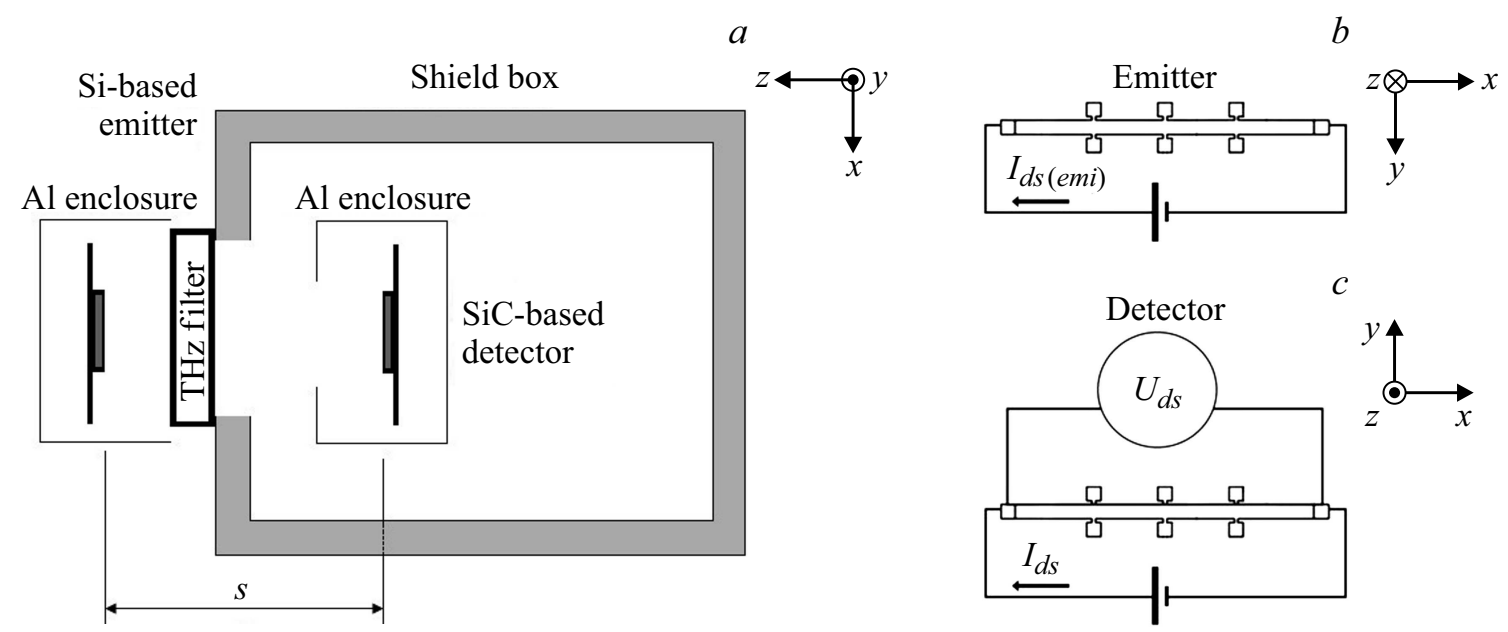

Рис. 2. $a$ - взаимное расположение источника излучения на основе $\mathrm{Si}$ и детектора ТГц излучения на основе $\mathrm{SiC}$; $s-\mathrm{paccтояние}$ между образцами. $b-$ схема пропускания продольного тока исток-сток $I_{d s(e m i)}$ через образец-источник. $c-$ схема пропускания продольного тока исток-сток $I_{d s}$ через образец-детектор и измерения продольного напряжения $U_{d s}$ детектора.

ТГц излучения использовался наносандвич на основе кремния, сильно легированного бором, который содержит сверхузкую кремниевую квантовую яму шириной 2 нм, ограниченную двумя $\delta$-барьерами, содержащими дипольные центры бора с отрицательной корреляционной энергией [27]. Источник имеет геометрию холловского мостика, аналогичную показанной на рис. 1, и характеризуется параметрами (в мкм) $a=50, b=200$, $d=200, l=4720, f=1000$. Генерация источником ТГц излучения происходит при пропускании через него продольного тока исток-сток $I_{d s(e m i)}$ (рис. $\left.2, b\right)$ в миллиамперном диапазоне [27]. Оба образца помещались внутрь алюминиевых корпусов с отверстием и располагались плоскостями друг напротив друга.

В эксперименте измерялось в зависимости от времени продольное напряжение $U_{d s}$ детектора в условиях пропускания продольного тока исток-сток $I_{d s}=1.5$ мкА (рис. 2,c). Измерения проходили при комнатной температуре. За один проход проводилось от 580 до 1500 измерений с общей длительностью от 245 до 634 с соответственно, причем в первые 200 измерений ТГц излучение отсутствовало, а начиная с 201-го падало на детектор в условиях подачи на источник продольного тока $I_{d s(e m i)}=30 \mathrm{MA}$. Вследствие этого для анализа использовалась величина

$$
\Delta U_{d s}=U_{d s}-\left\langle U_{d s}(1-200)\right\rangle
$$

равная разности экспериментального значения $U_{d s}$ и его среднего значения от первых двухсот измерений.

\section{3. Результаты и обсуждение}

Результаты измерений показаны на рис. 3, где вертикальной чертой на отметке Counts $=200$ показан момент начала генерации излучения при подаче тока на источник. При различных расстояниях $s=42$ (рис. $3, a$ ),
36 (рис. $3, b), 30$ мм (рис. $3, c)$ в кинетической зависимости $\Delta U_{d s}(t)$ наблюдается воспроизводимость характерных ступенчатых особенностей. Далее предлагается возможная модель, в рамках которой возникающие особенности $\Delta U_{d s}(t)$ связываются с величиной принимаемого излучения с помощью формулы Фарадея. Особенностью данного эксперимента является возможность захвата на области квантовой интерференции одиночных квантов магнитного потока, что проявляется в обнаруженных осцилляциях магнитной восприимчивости, период которых зависит от размеров области квантовой интерференции [25]. Таким образом, можно говорить о квантовом эффекте Фарадея, возникающем вследствие захвата одиночных квантов магнитного потока (силовых линий магнитного поля) в области квантовой интерференции.

Из измерений в магнитном поле можно оценить характерный размер $L$ области квантовой интерференции носителей. По данным магнетополевых зависимостей продольного напряжения $U_{x x}$ исследуемого образца область интерференции одиночного носителя в краевом канале имеет размеры 134 мкм $\times 1.54$ нм [16]. Если принять во внимание возможность сильного подавления электрон-электронного взаимодействия вследствие отмеченного выше сильного давления, порядка сотен ГПа, на границе кремниевая подложка-карбид кремния, возможно формирование вдвое больших областей интерференции, содержащих пару носителей, то при этом оказывается $L_{1}=268$ мкм. Из измерений осцилляций магнитной восприимчивости можно оценить характерные размеры областей, в которых также может происходить интерференция пар носителей:

$$
R^{2}=\frac{\Phi_{0}}{\pi \Delta B}
$$

где $\Phi_{0}=h / 2 e-$ квант магнитного потока, $\Delta B-$ период осцилляций магнитной восприимчивости. Обнаруженные величины периодов 13 и $300 Э$ [25] приводят к 
Counts

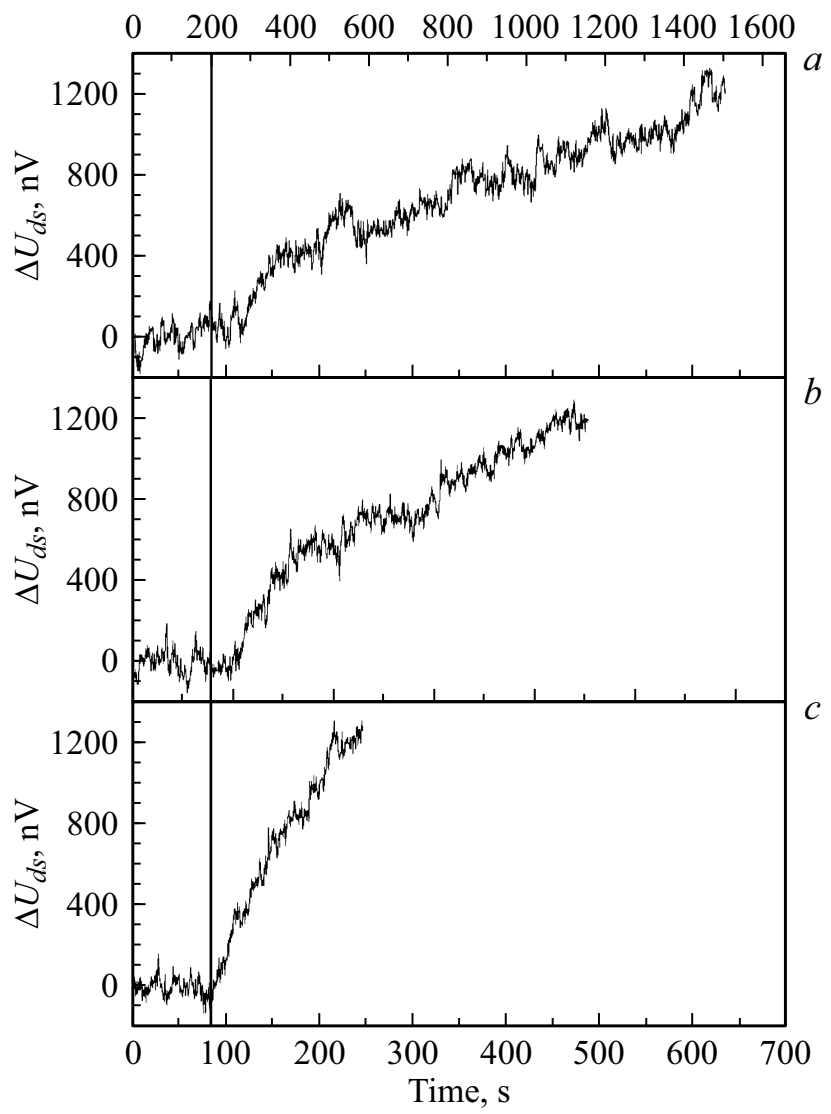

Рис. 3. Зависимость $\Delta U_{d s}(t)$ для детектора на основе $\mathrm{SiC}$ при значениях расстояния $s=42(a), 36(b), 30$ мм (c). Ступенчатые особенности 400, $1200 \mathrm{HB}$ отвечают детектированию частот 2.745 ТГц и 9.096 ГГц. Вертикальной чертой показан момент начала генерации излучения при включении тока $I_{d s(\text { emi })}=30 \mathrm{MA}$ на источнике. Температура $T=300 \mathrm{~K}$, $I_{d s}=1.5$ мкA.

значениям $R$, равным 0.712 и 0.148 мкм соответственно, откуда для характерного размера $L=2 R$ области интерференции получаем $L_{2}=1.424$ мкм и $L_{3}=0.296$ мкм.

Зная характерные размеры областей квантовой интерференции пар носителей, можно связать полученные особенности в $\Delta U_{d s}(t)$ с частотой падающего излучения с помощью формулы Фарадея:

$$
I_{g e n}=\frac{\Delta E}{\Delta \Phi}=\frac{h v}{\Phi},
$$

где $I_{g e n}-$ генерационный ток, возникающий при внесении в систему дополнительной энергии $\Delta E$ в условиях наличия изменения магнитного потока $\Delta \Phi$. Для пары носителей в условиях захвата одиночных силовых линий на область квантовой интерференции справедливо соотношение $\Delta \Phi=\Phi_{0}=h / 2 e(\Delta \Phi=\Delta B \cdot S$, где $\Delta B-$ изменение магнитного поля при захвате одиночного кванта магнитного потока $\Phi_{0}$ на область квантовой интерференции площадью $S$ ). Поэтому генерационный ток, возникающий вследствие падающего на детектор излучения, связывается с соответствующим значением напряжения через квант проводимости $G_{0}=2 e^{2} / h$ следующим образом: $I_{g e n}=2 G_{0} U$. В итоге можно оценить значение частоты падающего излучения:

$$
v=N \cdot G_{0} \Delta U_{d s} / e,
$$

где $N=L_{0} / L_{i}-$ число параллельно включенных областей квантовой интерференции с соответствующим характерным размером $L_{1,2,3}$ на длине $L_{0}$ между измерительными контактами. В случае $d s$-контактов $\quad L_{0}=l=4200$ мкм. Особенность $\Delta U_{d s}=400 \mathrm{HB}$ описывает вклад в генерационный ток областей с $L_{3}=0.296$ мкм, что приводит к значению $v=2.745$ ТГц. Особенность $\Delta U_{d s}=1200 \mathrm{HB}$ описывает вклад в генерационный ток областей с $L_{1}=268$ мкм, что приводит к значению $v=9.096$ ГГц.

Чтобы разрешить более мелкие особенности, можно проводить измерения по той же схеме, но с использованием $x x$-контактов в качестве измерительных (см. рис. 1). Результат такого измерения показан на рис. 4. В этом случае $L_{0}=2 f=2000$ мкм, и особенность $\Delta U_{d s}=220 \mathrm{нB}$ описывает вклад в генерационный ток областей с $L_{2}=1.424$ мкм, что приводит к значению $v=0.15$ ТГц. Полученные значения хорошо согласуются с ключевыми частотами образца-источника 2.8 , 0.12 ТГц и 9.3 ГГц [27].

Следует отметить, что в отклике детектора на внешнее ТГц излучение может присутствовать составляющая, обусловленная собственной генерацией ТГц излучения вследствие протекания продольного тока по краевым каналам. В этом случае изменение энергии в формуле (4) определяется величиной нагрузочного сопротивления в области квантовой интерференции. Иными словами,

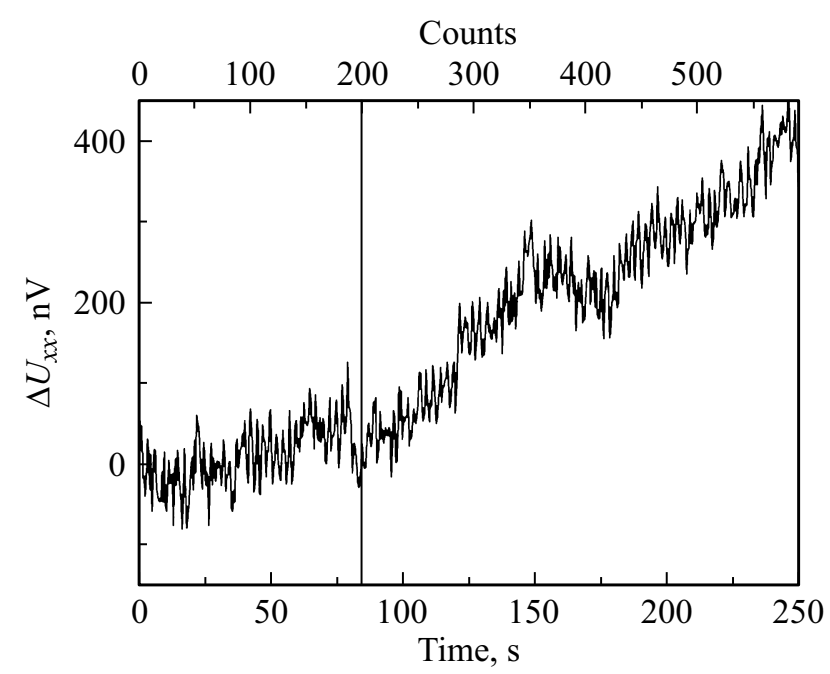

Рис. 4. Зависимость $\Delta U_{x x}(t)$ для детектора на основе $\mathrm{SiC}$ при $s=30$ мм. Ступенчатая особенность $220 \mathrm{HB}$ отвечает детектированию частоты 0.15 ТГц. Вертикальной чертой показан момент начала генерации излучения при включении тока $I_{d s(\text { emi })}=30 \mathrm{MA}$ на источнике. Температура $T=300 \mathrm{~K}$, $I_{d s}=1.5 \mathrm{M \kappa A}$. 


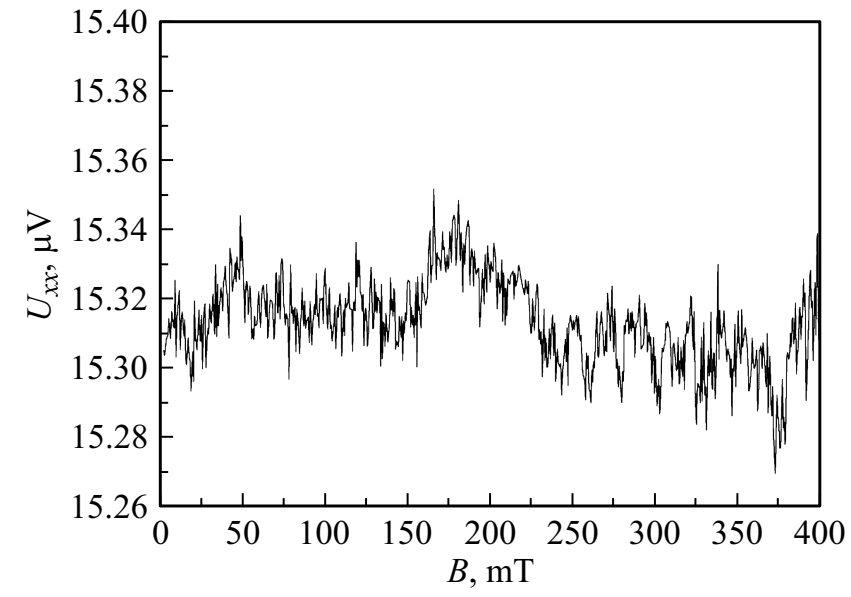

Рис. 5. Спектр ЭДЭПР образца-детектора, зарегистрированный с помощью измерения продольного напряжения $U_{x x}$. Особенность на 162.5 мТ соответствует частоте 3.4 ТГц. Температура $T=300 \mathrm{~K}, I_{d s}=10 \mathrm{HA}$.

электрические характеристики в области квантовой интерференции определяют частоту возникающей генерации, которую можно оценить путем идентификации спектра электрически детектируемого электронного парамагнитного резонанса (ЭДЭПР) при измерении магнетополевых зависимостей продольного напряжения [28]. При пропускании через образец, выполненный в рамках холловской геометрии, тока исток-сток в наноамперном диапазоне возникает СВЧ генерация в краевом канале при наличии встроенных в него микрорезонаторов [28]. При этих условиях сканирование магнитного поля дает спектр ЭДЭПР точечных центров, локализованных внутри краевых каналов.

Результаты измерений представлены на рис. 5, где показана зависимость напряжения $U_{x x}$ исследуемого образца-детектора от величины магнитного поля $B$, приложенного перпендикулярно плоскости образца, в условиях $I_{d s}=10$ нА при комнатной температуре. Анализ спектра ЭДЭПР на рис. 5 показывает, что он содержит фрагмент магнетополевой зависимости, соответствующий спектру ЭПР кремниевой вакансии, зарегистрированному при частоте 9.4ГГц (рис. 6) [29]. Тем самым подтверждается наличие микрорезонаторов, обеспечивающих генерацию и прием излучения сантиметрового диапазона длин волн. В исследуемом образце в качестве микрорезонатора с геометрической длиной $l_{0}$, по-видимому, выступает кремниевая подложка на длине образца: с учетом значения 3.42 для показателя преломления в кремнии (база данных NSM [30]) условие $l_{0}=c / 2 v n$ для частоты $v=9.3$ ГГц дает $l_{0}=4.74 \mathrm{Mм}$, что хорошо согласуется со значением $l+2 b$ длины образца с учетом размеров контактных площадок (см. рис. 1).

В отличие от моночастотного ЭДЭПР, при возможности создания нескольких типов микрорезонаторов и наличии ряда областей квантовой интерференции разной площади, в которых происходит генерации излучения, может быть реализована многочастотная версия ЭДЭПР. При этом регистрируемая магнетополевая зависимость будет показывать многообразие генерируемых частот в областях квантовой интерференции. Так, низкополевая часть спектра ЭДЭПР, приведенного на рис. $5, g=1500$, соответствует генерации излучения с частотой 3.4 ТГц, которая была обнаружена в спектре электролюминесценции исследуемого образца [16].

При этом вследствие разницы в размерах соответствующих микрорезонаторов, 17.3 мкм (см. рис. 9 в [16]), и площади, занимаемой одиночным носителем в краевом канале, 134 мкм $\times 1.54$ нм [16], спектр ЭДЭПР оказывается расщепленным на 7 компонент. При этом возбужденные состояния комплексов кремниевых вакансий, взаимодействующих с одиночными носителями, отчетливо проявляются в форме линий разной полярности в сильном и слабом магнитном полях, наличие которых свидетельствует об их сильной спиновой поляризации.
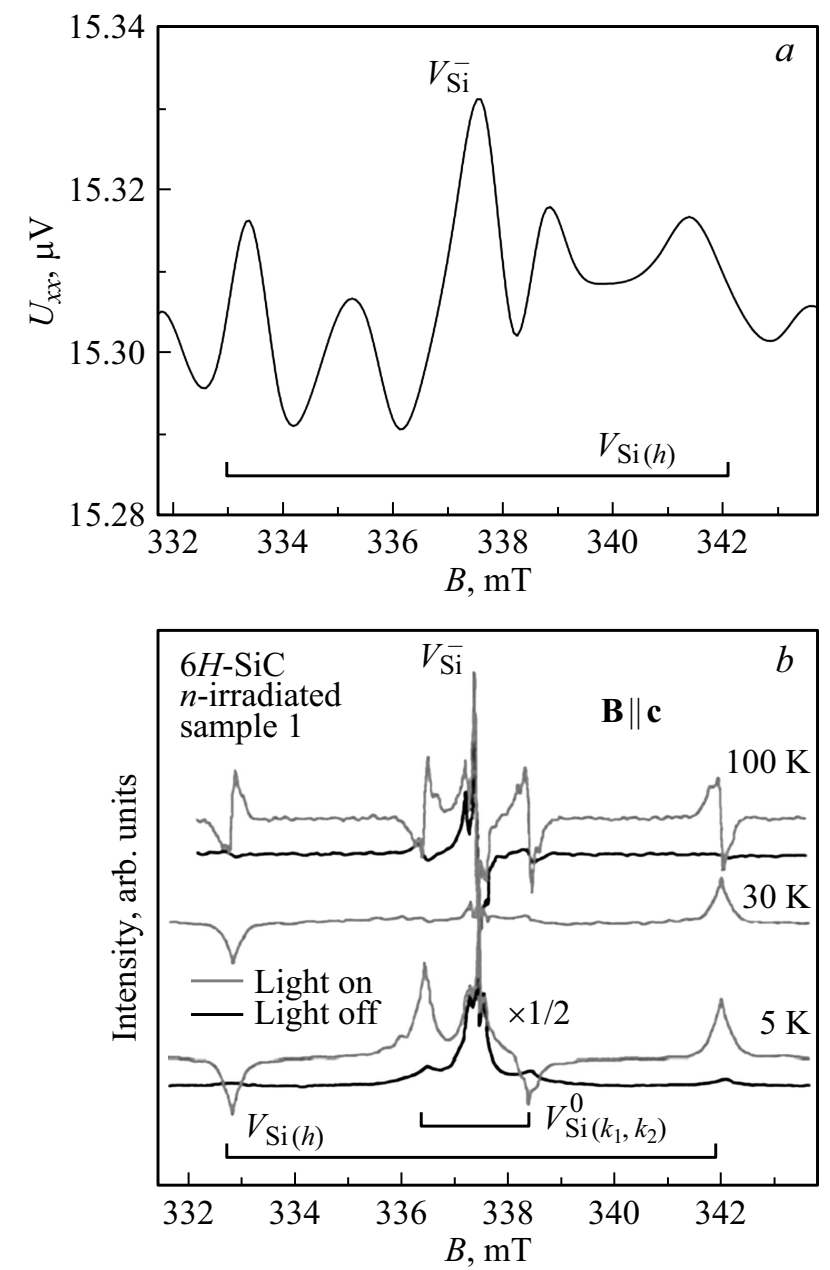

Рис. 6. $a-$ спектр ЭДЭПР кремниевой вакансии в образцедетекторе, зарегистрированный с помощью измерения продольного напряжения $U_{x x}$ без использования внешнего резонатора, источника и приемника СВЧ; $T=300 \mathrm{~K}, I_{d s}=10 \mathrm{HA}$. $b$ - спектр ЭПР (X-диапазон) вакансии кремния в $6 H$-SiC (по данным работы [29]). 
Следует отметить, что устойчивая регистрация ЭДЭПР многокомпонентных вакансионных центров в условиях обменного взаимодействия с носителями выполняется при условии малого значения эффективной массы носителя в краевом канале:

$$
\hbar \omega_{c}=2 \pi \nu \hbar=\hbar \frac{e \Delta B}{m^{*}},
$$

где $m^{*}$ - эффективная масса носителя в краевом канале, $v$ - значение частоты регистрации спектра ЭДЭПР, $\Delta B$ - полуширина спектра ЭДЭПР, $e-$ заряд электрона. Оценка эффективной массы из данной магнетополевой зависимости на рис. 5 при $\Delta B=6.5$ мТ и $v=3.4$ ТГц приводит к значению $m^{*}=5 \cdot 10^{-35}$ кг, что соответствует данным измерений осцилляций дГвА [25]. Таким образом, наблюдение ЭДЭПР реально возможно при малой эффективной массе носителей, что соответствует условиям транспорта в краевых каналах и квазиодномерных структурах.

\section{4. Заключение}

Таким образом, обнаружены и исследованы эффекты отклика наноструктур карбида кремния, полученных методом согласованного замещения атомов, на внешнее ТГц излучение, которые проявлялись при регистрации кинетической зависимости продольного напряжения при комнатной температуре в условиях пропускания продольного тока исток-сток в структурах с холловской геометрией. Обнаруженные особенности кинетических зависимостей продольного напряжения рассмотрены в рамках квантового эффекта Фарадея, возникающего при захвате одиночных квантов магнитного потока в краевые каналы наноструктур. В рамках предлагаемой модели ТГц излучение приводит к генерации тока в краевом канале и соответственно к изменению в кинетических зависимостях продольного напряжения, которые определяются геометрическими параметрами исследуемых наноструктур.

Методика регистрации ЭДЭПР путем измерения магнетополевых зависимостей продольного напряжения позволила обнаружить генерацию собственного ТГц излучения из наноструктур карбида кремния, возникающего в условиях пропускания продольного тока исток-сток. Показано, что наличие микрорезонаторов, встроенных в краевые каналы наноструктуры, обеспечивает генерацию и прием ТГц излучения. Устойчивая регистрация спектров ЭДЭПР возможна при малом значении эффективной массы носителей в краевом канале исследуемой структуры.

\section{Финансирование работы}

Работа выполнена при финансовой поддержке гранта РНФ (грант № 20-12-00193).

\section{Благодарности}

Синтез слоя $\mathrm{SiC}$ на $\mathrm{Si}$ проводился с использованием оборудования уникальной научной установки „Физика, химия и механика кристаллов и тонких пленок“ ФГУП ИПМаш РАН (Санкт-Петербург).

\section{Конфликт интересов}

Авторы заявляют, что у них нет конфликта интересов.

\section{Список литературы}

[1] M. Danciu, T. Alexa-Stratulat, C. Stefanescu, G. Dodi, B.I. Tamba, C. Teodor Mihai, G.D. Stanciu, A. Luca, I.A. Spiridon, L.B. Ungureanu, V. Ianole, I. Ciortescu, C. Mihai, G. Stefanescu, I. Chirila, R. Ciobanu, V.L. Drug. Materials (Basel, Switzerland), 12 (9), 1519 (2019).

[2] X. Yang, X. Zhao, K. Yang, Y. Liu, Y. Liu, W. Fu, Y. Luo. Trends Biotechnol., 34, 810 (2016).

[3] O.P. Cherkasova, D.S. Serdyukov, A.S. Ratushnyak, E.F. Nemova, E.N. Kozlov, Yu.V. Shidlovskii, K.I. Zaytsev, V.V. Tuchin. Opt. Spectrosc., 128 (6), 855 (2020).

[4] S.A. Il'ina, G.F. Bakaushina, V.I. Gaiduk, A.M. Khrapko, N.B. Zinov'eva. Biofizika, 24, 513 (1979).

[5] L.V. Titova, A.K. Ayesheshim, A. Golubov, R. RodriguezJuarez, R. Woycicki, F.A. Hegmann, O. Kovalchuk. Sci. Rep., 3, 1 (2013).

[6] J. Xie, W. Ye, L. Zhou, X. Guo, X. Zang, L. Chen, Y. Zhu. Nanomaterials, 11, 1646 (2021).

[7] J. Kim, S.R. Moon, S. Han, S. Yoo, S.H. Cho. Opt. Express, 28, 23397 (2020).

[8] T. Harter, C. Fullner, J.N. Kemal, S. Ummethala, M. Brosi, E. Bründermann, W. Freude, S. Randel, C. Koos. 110-m THz Wireless Transmission at $100 \mathrm{Gbit} / \mathrm{s}$ Using a KramersKronig Schottky Barrier Diode Receiver. In: Proc. Eur. Conf. on Optical Communication (ECOC), (Roma, Italy, 2018).

[9] R.A. Lewis. J. Phys. D: Appl. Phys., 52, 433001 (2019).

[10] L. Ozyuzer, A.E. Koshelev, C. Kurter, N. Gopalsami, Q. Li, M. Tachiki, K. Kadowaki, T. Yamamoto, H. Minami, H. Yamaguchi, T. Tachiki, K.E. Gray, W.-K. Kwok, U. Welp. Science, 318, 1291 (2007).

[11] M. Dyakonov, M. Shur. IEEE Trans. Electron Dev., 43 (3), 380 (1996).

[12] T. Taimre, M. Nikolić, K. Bertling, Y.L. Lim, T. Bosch, A.D. Rakić. Adv. Opt. Photon., 7, 570 (2015).

[13] Y.L. Lim, T. Taimre, K. Bertling, P. Dean, D. Indjin, A. Valavanis, S.P. Khanna, M. Lachab, H. Schaider, T.W. Prow, H.P. Soyer, S.J. Wilson, E.H. Linfield, A.G. Davies, A.D. Rakić. Biomed. Optics Express, 5 (11), 3981 (2014).

[14] K.B. Taranets, M.A. Fomin, L.E. Klyachkin, A.M. Malyarenko, N.T. Bagraev, A.L. Chernev. J. Appl. Phys., 125, 225702 (2019).

[15] Н.Т. Баграев, Л.Е. Клячкин, А.А. Кудрявцев, А.М. Маляренко, В.В. Романов. ФТП, 43 (11), 1481 (2009).

[16] Н.Т. Баграев, С.А. Кукушкин, А.В. Осипов, Л.Е. Клячкин, А.М. Маляренко, В.С. Хромов. ФТП, 55 (11), 1027 (2021).

[17] С.А. Кукушкин, А.В. Осипов. ФТТ, 50, 1188 (2008).

[18] С.А. Кукушкин, А.В. Осипов. ДАН, 444, 266 (2012).

[19] С.А. Кукушкин, А.В. Осипов. Изв. РАН. Механика твердого тела, № 2, 122 (2013). 
[20] S.A. Kukushkin, A.V. Osipov. J. Phys. D: Appl. Phys., 47 (31), 313001 (2014).

[21] С.А. Кукушкин, А.В. Осипов, Н.А. Феоктистов. ФТТ, 56, 1457 (2014).

[22] S.A. Kukushkin, A.V. Osipov. J. Phys. D: Appl. Phys., 50 (46), 464006 (2017).

[23] Л.М. Сорокин, Н.В. Веселов, М.П. Щеглов, А.Е. Калмыков, А.А. Ситникова, Н.А. Феоктистов, А.В. Осипов, С.А. Кукушкин. Письма ЖТФ, 34 (22), 88 (2008).

[24] С.А. Кукушкин, А.В. Осипов. Письма ЖТФ, 46 (22), 3 (2020).

[25] Н.Т. Баграев, С.А. Кукушкин, А.В. Осипов, В.В. Романов, Л.Е. Клячкин, А.М. Маляренко, В.С. Хромов. ФТП, 55 (2), $103(2021)$

[26] N.T. Bagraev, V.Yu. Grigoryev, L.E. Klyachkin, A.M. Malyarenko, V.A. Mashkov, V.V. Romanov. Semiconductors, 50 (8), 1025 (2016).

[27] Н.Т. Баграев, Л.Е. Клячкин, А.М. Маляренко, Б.А. Новиков. Биотехносфера, 5 (41), 55 (2015).

[28] Н.Т. Баграев, Д.С. Гец, Е.Н. Калабухова, Л.Е. Клячкин, А.М. Маляренко, В.А. Машков, Д.В. Савченко, Б.Д. Шанина. ФТП, 48 (11), 1503 (2014).

[29] P.G. Baranov, A.P. Bundakova, A.A. Soltamova, S.B. Orlinskii, I.V. Borovykh, R. Zondervan, R. Verberk, J. Schmidt. Phys. Rev. B, 83, 125203 (2011).

[30] http://www.ioffe.ru/SVA/NSM

Редактор Л.В. Шаронова

\section{Registration of terahertz radiation with silicon carbide nanostructures}

N.T. Bagraev ${ }^{1,2}$, S.A. Kukushkin ${ }^{1}$, A.V. Osipov ${ }^{1}$, L.E. Klyachkin ${ }^{2}$, A.M. Malyarenko ${ }^{2}$, V.S. Khromov ${ }^{1,2}$

${ }^{1}$ Institute for Problems in Mechanical Engineering, Russian Academy of Sciences, 199178 St. Petersburg, Russia

2 loffe Institute, 194021 St. Petersburg, Russia

\footnotetext{
Abstract The response to external terahertz radiation from silicon carbide nanostructures prepared by the method of substitution of atoms on silicon is investigated. The kinetic dependence of the longitudinal voltage is recorded at room temperature by varying the drain-source current in the device structure performed in the Hall geometry. In the frameworks of proposed model based on the quantum Faraday effect, the incident radiation results in the appearance of a generated current in the edge channels with a change in the number of magnetic flux quanta and in the appearance of features in the kinetic dependence of the longitudinal voltage. The generation of intrinsic terahertz radiation inside the silicon carbide nanostructures is also revealed by the electrically-detected electron paramagnetic resonance (EDEPR) through measuring the longitudinal voltage as a function of magnetic field.
} 